\title{
Older people's perspectives on living in integrated housing and care settings: the case of extra care housing
}

\author{
Ailsa Cameron and Eleanor K Johnson \\ School for Policy Studies, University of Bristol, Bristol, UK, and \\ Simon Evans \\ University of Worcestershire, Worcester, UK
}

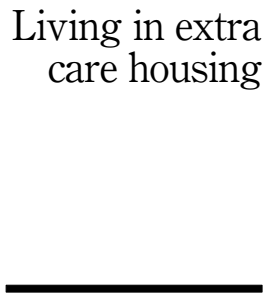

Received 6 September 2019

Revised 13 March 2020

Accepted 30 March 2020

\begin{abstract}
Purpose - This paper explores residents' perceptions and experiences of extra care housing as an integrated model of housing with care.

Design/methodology/approach - Data were collected in a longitudinal qualitative study based on four extra care housing schemes. Data from interviews with residents, care workers, managers and local commissioners were analysed thematically.

Findings - The integration of housing with care enabled many older people to manage their care proactively. However, the increasing number of residents with complex health and care needs, including chronic illness, led some residents to question the ability of the model to support residents to live independently.

Research limitations/implications - The study struggled to recruit sufficient residents from the specialist dementia setting who were able to communicate their consent to take part in the research. In addition, the quality of qualitative data collected in interviews with participants at this setting reduced over successive rounds of interviews.

Practical implications - The study suggests the need to ensure that residents are fully informed about levels of care and support is available when considering a move into extra care housing.

Originality/value - This paper provides a timely opportunity to consider extra care housing as an example of an integrated housing service, particularly in light of the current challenges facing the sector.
\end{abstract}

Keywords Extra care housing, Integration, Older people

Paper type Research paper

\section{Background}

Over the past 20 years, there has been increasing interest in the role of joined-up services in England as well as internationally (Mann et al., 2019). In part this reflects the growing demand for services and concerns about the cost-effectiveness of service provision, but it also reflects a recognition that the problems people experience may be addressed more effectively and efficiently if agencies and professionals work together. In recent years this interest has been framed as integration, the bringing together of agencies and professionals to deliver coordinated person-centred services (DH, 2013). Originally the focus was almost exclusively on integrating health and social care, but, in response to the growing numbers of older people

(C) Ailsa Cameron. Published by Emerald Publishing Limited. This article is published under the Creative Commons Attribution (CC BY 4.0) licence. Anyone may reproduce, distribute, translate and create derivative works of this article (for both commercial \& non-commercial purposes), subject to full attribution to the original publication and authors. The full terms of this licence may be seen at http:// creativecommons.org/licences/by/4.0/legalcode

This article presents independent research funded by the NIHR School for Social Care Research. The views expressed in this publication are those of the authors and not necessarily those of the NIHR School for Social Care Research or the Department of Health and Social Care, NIHR or NHS.

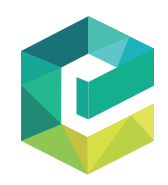

Journal of Integrated Care Emerald Publishing Limited DOI 10.1108/JICA-09-2019-0040 
wanting to live independently and recognition of the relevance of housing to health and wellbeing, increasing attention has been paid to the role of housing and care. This paper explores older people's experiences and perspectives on extra care housing $(\mathrm{ECH})$, an integrated model of housing and care, to consider the advantages and disadvantages of this approach.

\section{Introduction}

An expansion in the population aged over 65 living in England, increases in the number of people living with complex care needs and an expectation that the number of older people living independently will rise substantially over the next two decades, taken together, place increasing pressure on health and social care services (Kingston et al., 2018). A key element of this pressure is the growing recognition of the need for a variety of housing models to support older people to live independently. Such is the significance now placed on the role of housing in supporting older people that, in England, the Care Act 2014 states that housing is an essential element of local authorities' duty to promote integrated provision. Indeed, the Care Act identifies registered providers of social housing as partners, with whom local authorities must cooperate when considering and planning a person's need for care and support. As such, national policy has now begun to formally recognise that appropriate housing can help ensure that older people live as independently as possible and that their needs for social care are reduced (Age UK, 2019).

\section{What is integration?}

In the context of health and social care policy and practice, the drive towards integration is long-standing. Policy has consistently emphasised the need for services to be joined up, believing that integrated services will be more effective and more efficient (DH, 2013). However, the evidence base for integrated health and social care services, nationally as well as internationally, is less than conclusive (Looman et al., 2019). Indeed, the National Audit Office in the United Kingdom has reported that government has "not yet established a robust evidence base to show that integration leads to better outcomes for patients" (NAO, 2017, p. 7). In contrast, the evidence base reporting on the process of integration, specifically the factors known to support or hinder integration, is better established. Factors known to support integration include the co-location of services; clear communication and good understanding of, and commitment to, the model. Factors reported to undermine the success of integrated services include a lack of stability in the policy and organisational context as well as inadequate funding (Cameron, 2016).

Despite the lack of robust evidence in relation to the outcomes of integrated health and social care services, policymakers and practitioners' enthusiasm for integrated services has not diminished (DH, 2017). In recent years, increasing attention, both in England and internationally, has focussed on the boundaries between housing and social care (Wild et al., 2018). In relation to housing for older people, various models of what is known as housing with care have evolved aimed at providing older people with more housing options in later life (Atkinson et al., 2014). One such model is extra care housing (ECH), an integrated model of housing with social care that was originally conceived to promote healthy ageing by supporting older people to live independently in a self-contained apartment within a communal setting, while also having access to care and support if required (Atkinson et al., 2014).

\section{Extra care housing as a model of integration}

ECH is generally understood as a form of housing for adults over the age of 55 that affords residents “... specific tenure rights to occupy self-contained dwellings and where they have 
agreements that cover the provision of care, support, domestic, social, community or other services" (Housing LIN, 2015, p. 3). Most ECH schemes have an on-site care team delivering planned care and support to residents on a flexible basis responding to their changing needs as they emerge, reinforcing the idea of ECH as a home for life. Significantly, residents of ECH are not obliged to get their care from a specified provider unlike those living in residential care homes. "Care" in this context only extends to personal care and support, for example, assistance to get washed and dressed as well as help with medical matters that, as Batty et al. describe, "do not require a trained medical professional" (2017, p. 4). Most schemes also offer communal facilities such as a restaurant and lounges and some have extensive social facilities such as IT suites and exercise facilities. ECH is generally available in a variety of tenure types - including social rent, market rent, leasehold and shared ownership - and is provided by housing associations, local authorities, charities and private providers (Housing LIN, 2015). Integrated housing and care models, such as ECH, are available in many countries including North America and Australia where they are often known as "assisted living" or "senior housing" (Atkinson et al., 2014).

Unlike traditional residential care, ECH aims to promote informal care and self-care through the integration of housing with care within a resident's own private apartment to maximise their capacity for independent living (Housing LIN, 2015). Formal care and support are provided as and when they are needed so that residents can avoid "the pitfalls" of remaining in inappropriate housing (Callaghan and Towers, 2014, p. 1429). In order to ensure that ECH settings function as a community that supports the independence of those who live there, managers and commissioners have tended to seek a balance of care needs amongst residents: those with no or minimal care needs; those with medium-level needs and those with high-level care needs (Wright et al., 2010). However, the financial pressures facing authorities have meant that priority access for publicly funded ECH residents is often given to those with higher care needs, thus undermining any sense of a balance of care needs amongst residents and potentially impacting how the community functions (Cameron et al., 2019).

Despite the increasing role of housing in care policy, Wild et al. (2018) argue that there is limited evidence of its impact, specifically in relation to the integration of services. For example, a longitudinal study undertaken for the ExtraCare Charitable Trust suggests that social care costs for those living in extra care are lower than those in housing in the community while also indicating that average National Health Service (NHS) costs for those in $\mathrm{ECH}$ reduced more over 12 months than for those living in the community (Holland et al., 2015). However, a comparative study of older people living in ECH, residential care and the community found that residents of ECH were less satisfied with the social care they received than those who used traditional services (Phillips et al., 2015). In contrast, more recent studies found that residents compared living in ECH settings favourably to residential care and other forms of specialist housing (Batty et al., 2017) as well as reductions in the use of health services and associated resources and significant cost benefits for the health system from the use of housing with care services (Housing LIN, 2019).

\footnotetext{
Methods

This article presents findings from the Provision of Social Care in Extra Care Housing (ECHO) project, a longitudinal qualitative study designed to investigate how care is negotiated and delivered in ECH. Four ECH settings were recruited from two regions of England chosen to reflect the different pressures facing the sector. Sites A and B were based in a unitary authority facing increased pressure on land - residents at both sites were predominantly publicly funded. Site C, a specialist dementia setting, and site D were based in the county council with over provision in ECH. Residents of site $\mathrm{C}$ were primarily publicly funded, while at site D most were owner-occupiers.
} 
Data were gathered through interviews. Residents were interviewed four times over 20 months, beginning in January 2016. Managers of schemes and commissioners were interviewed twice, at the beginning and the end of the study, and care workers were interviewed once. An introductory meeting was held with residents and staff at each site prior to fieldwork, to recruit participants. This paper presents findings from the interviews with residents.

In total, 51 residents (10 men and 41 women) participated in the study (14 at site A, 12 at site $B, 11$ at site $C$ and 14 at site $D$ ), ranging in age from 54 to 97 . Base-line interviews explored why residents had moved into ECH, health status, need for care and support and involvement in social activities. Subsequent interviews focussed on changes in the need for care and support and experiences of receiving these services. Interviews lasted between 25 and $75 \mathrm{~min}$ and were recorded and transcribed. A sample of transcripts were read by three members of the team to develop a coding frame which incorporated a priori codes and supplemented with themes emerging inductively. The full data set was coded (EJ) and then organised in relation to emerging themes such as the need for care (Spencer et al., 2014), data were managed using NVivo software.

Ethical approval was granted by the Social Care Research Ethics Committee (15/IEC08/ 0047). All participants gave written consent prior to each interview with capacity to consent established using Dewing's (2008) five-step process. Over the course of the study, ten participants withdrew, of whom three were determined to no longer have capacity to consent, three died, two entered residential care and two chose to withdraw.

\section{Findings}

This paper explores residents' perceptions of how the integration of housing with care works in practice. We begin by discussing how the ECH model adapts to temporary and permanent changes in residents' needs for care before exploring whether the model can accommodate individuals with more complex care or support needs.

\section{Temporary changes in care}

The integrated nature of care and support within ECH settings was intended to ensure that care can be provided on a flexible basis, responding to residents' changing needs for care as they emerge. For many residents these changes were temporary. Several residents reported receiving care for a short period, for example, as they recuperated after hospitalisation, resident 4 at Site B said:

I had it [support] when I came out of hospital ... They took me shopping. They did a little bit of cleaning for me. All the rest I did myself . ... I had that [care] for quite a few weeks. Six weeks I think it was.

But care might be required on a temporary basis for other reasons. Resident 11 at site $\mathrm{D}$ who lived with, and cared for, her partner living with dementia, described how she would soon be admitted to hospital and while she was there, she had arranged for the care team where she lived to look after her partner. On her return the team would also provide care and support to her while she recuperated. She described:

They'll care for him while I'm at [name of hospital]. Well, my sister's coming, but I'll get him used to going down to the restaurant and I'll have the housekeepers clean twice a week or once a week, and the carers will look after me. They're not nurses, but they can help me shower and wash my hair and that sort of thing; help me dress, if this arm is a bit disabled. But it means I can come home earlier than.

This example demonstrates that not only does ECH attend to the personal needs for care and support but, as in this case, it may lessen feelings of anxiety and loss of control that residents 
with caring responsibilities themselves experience when their own needs for care emerge. Had this couple not been living in an integrated model of housing with care, organising a temporary package of care that met the different needs of both residents might not have been as straightforward.

\section{Permanent changes in care needs}

Many of the older people in the study moved into ECH with existing care needs, receiving care and support daily. For some residents the package of care they received increased due to a permanent change in their need for care. For example, resident 2 at Site D received care daily; however, following a fall she began receiving additional support to help her move around the scheme and participate in social activities. She described:

I have a shower in the morning, every morning seven days a week and they help me with my medication, and I had a fall last October and since then ... I am generally accompanied up and downstairs ... I am fully recovered from that but now, that's the sort of care I get and I am very happy with it.

Receiving additional care and support in this integrated manner enabled many residents to live a more independent life and take part in the social activities available at their settings. Unfortunately, this was not the case for all residents across the four schemes. When asked if there was anything that stopped her participating in activities at site B, for example, resident 3 , who received care every day, told us:

Well only my health I suppose. The fact that I can't do anything, I mean I can just walk from here to downstairs with the aid of my walker. And of course, if you fall down here ... you've got to wait, an ambulance has got to come ... to pick you up. Then they take you to hospital, make sure you're alright.

In other words, there might not have been sufficient support available to some residents to enable them to take part in the daily life of the ECH scheme where they live.

\section{ECH and healthcare provision}

One of the main distinctions between ECH and traditional nursing home care is the absence of direct provision of healthcare by ECH staff, although a growing number of schemes have consulting rooms for general practitioners (GPs) and other health professionals. While care workers might remind, and support, a resident to take their medication or help them with tasks such as putting on support stockings, they do not officially provide direct healthcare, such as giving injections.

GPs and district nurses often visited residents but only when the need arose, as they would in the community. Indeed, just like any other member of the public, residents were encouraged to attend their local practice. However, not all residents appreciated why this was the case. For example, resident 3 at Site B was unhappy with being told to visit her local practice, she said:

Because I'm driving, they won't come to me now, the district nurses. Imean they used to come to treat my leg. I had a bad leg and they used to come, and times when I'd ring to make an appointment, she said "you ought to be going down to the clinic". I said "why?" "Because" she said, "you've got a car". I said ... "you don't realise the pain and what I go through to get to the clinic".

This resident was frustrated by the lack of on-site healthcare and the subsequent need to attend the GP practice, suggesting that the aim of ECH to support independent living, including attending external healthcare appointments, was not always understood. 
Can ECH cope with health needs?

Echoing previous research (Croucher et al., 2006), many residents, as well as staff, were concerned that the ECH settings were struggling to cope with some of the additional health needs that residents often experienced. There appeared to be several elements to this. First, some residents were concerned that, having lived in ECH for many years, they would have to move to another type of residential care setting as their health deteriorated, requiring more intensive healthcare provided by health professionals. This realisation caused anxiety. For example, resident 7 at site $\mathrm{B}$ who had progressive multiple sclerosis explained how he had moved into $\mathrm{ECH}$ for practical reasons, to do with the physical accessibility of the setting as well as the responsive and flexible provision of care. Living in ECH had provided him with a measure of control, allowing him to pursue his own interests in a way which enhanced his sense of independence. Resident 7 believed that this sense of independence would have been severely constrained had he moved into a traditional care setting. However, he was worried that as his condition deteriorated necessitating more frequent intensive healthcare, he would have to move into a care home, where he would have less independence. He explained:

what worries me is ... if you read about the things that could happen, because I have got progressive [multiple sclerosis], ... I am hoping to God that it's another 17 years before anything happens but the next thing that could happen could mean I could end up not being able to stay here. They would have to put me in a home and that thought fills me with dread.

Similar concerns were noted by participants in relation to other chronic health conditions such as cancer and dementia. It appeared that some residents did not appreciate the distinction between social care and healthcare in relation to particular health conditions, or perhaps these differences had not been sufficiently well explained to them.

Allied to this was a palpable sense across all sites, that more residents were moving into $\mathrm{ECH}$ with higher and more complex needs than in the past. In part, this might reflect the broader trend amongst older people, to delay moving into care (Darton et al., 2012). However, at sites $\mathrm{A}$ and $\mathrm{B}$, where there were a higher proportion of publicly funded residents, there was a view among residents and staff that a lack of appropriate residential care facilities in the region meant more adults with complex care needs, including mental health needs such as anxiety disorders, being referred into $\mathrm{ECH}$. Several participants questioned whether this was appropriate. For example, resident 8 at site B said:

This place is getting more like a nursing home every day ... people come in here and they cannot move around. . . . they stay in their flat all the time or in bed and I think there's a couple of hospital beds in here ... when I first came here people were more mobile. ... but nowadays there's people coming in here, they've got to have so much care so that means that they're not capable of doing a lot of things.

A further concern related to ECH's ability to cope with the growing number of residents who were living with dementia. Several participants reported that some residents with dementia never took part in the social aspect of the setting. This could undermine a central aim of ECH which is to support the participation of residents in the communal life of the setting. For example, resident 2 at site $B$ told us:

... .a lot [of residents] have got dementia. People coming in here, I got a feeling there's 49 flats and I haven't seen hardly any of them. They never come out of their flats. They go in their flat and they die in their flat or hospital, but they never mix so we don't know them.

While residents are not obliged to take part in the social activities provided in schemes, the growing number of residents who chose not to participate, or were unable to participate, may incrementally undermine the communal and social aspect of ECH. Supporting residents who live with dementia to engage in activities requires a staff group trained in person-centred 
dementia care and support as well as the adequate allocation of staff time to assist residents to access and participate in activities (Evans et al., 2018).

Some residents questioned whether non-specialist ECH schemes could offer a home for life for older people living with dementia. For example, resident 13 at site D described how another resident had recently had to move out. She said:

I'm just remembering the fact that the lady that we missed - we didn't know her name, we just knew her by sight, and we started enquiring what had happened to her. Now she hadn't actually died, she'd been moved on, and this begins to show shortcomings [in ECH] if you like. She'd had to be moved on, because she was suffering from dementia, and she couldn't be allowed to go out of the door on her own. But the whole ethic of independence says that she cannot be stopped from going out of the door on her own. And we definitely had the impression that there were facilities for every eventuality, didn't we? That whatever happened to us, we could stay here. In fact, it doesn't happen quite like that.

This suggests a dissonance between the lived experience of ECH and the expectations that some residents have when they move in, challenging the idea of ECH as a home for life (Evans et al., 2018). Residents at the specialist dementia site (site C) had similar concerns. For example, resident 11 negatively compared living in $\mathrm{ECH}$ to her previous experience of living in residential care, she said:

and it's $[\mathrm{ECH}]$ like living in your own flat, you're independent in your own flat and they have quarter hour slots to look after you. As I say I don't see anybody all day until half past seven when they come and give me a quarter of an hour. Now to me that's no way of looking after people.

\section{Discussion}

ECH is a model of integrated housing and care that was developed in order to provide older people with a greater choice of living arrangements in later life. Significantly, the values underpinning ECH are aligned with government aspirations in relation to supporting independence and autonomy amongst older people. This paper has demonstrated that ECH can support many older people to live as independently as possible, accessing care and support on a permanent or temporary basis when required. Many of the residents reported instances when they had proactively managed the care and support they received demonstrating how ECH can boost individual autonomy (Johnson et al., 2019). It could be argued that such flexibility is available to all older people, irrespective of the type of housing they live in and whether they are self-funders or publicly funded, through the existence of a care market. Nevertheless, the integration of care on-site provides some older people with a greater sense of flexibility, security and peace of mind than they would otherwise have found living in the community or in other types of residential settings (Batty et al., 2017).

However, while the research demonstrates that ECH continues to deliver care and support in ways that reflect many of the ideals espoused in policy, it also suggests that the integrated model of housing with care is under strain. Inevitably all services are influenced by the wider setting in which they are provided, and in common with other examples of integrated services, the ability of ECH to meet its aims is restricted by contextual factors (Cameron et al., 2016). For example, in England, changes to the long-term funding of housing support provided in ECH have undoubtedly restricted the level of support that is available to those residents who are publicly funded. Consequently, not only are the opportunities for some residents to take part in existing communal activities limited, but there may also be fewer funded activities available. In addition, the failure of central government to resolve the crisis related to the long-term funding of adult social care has resulted in some local authorities raising the eligibility criteria for services, including for
Living in extra care housing 
$\mathrm{ECH}$. As a result, older people with more complex needs, including less traditional needs, are being referred into ECH (Smith et al., 2017), undermining any notion of a balance of care needs amongst residents (West et al., 2017). Changes to the profile of residents will undoubtedly impact how the model operates, particularly in a period of reduced public spending (Evans et al., 2018).

Our findings suggest that the boundary between $\mathrm{ECH}$ and healthcare is problematic. It appears that for some older people the expectations they have of ECH may not be matched by the operationalisation of the model or by the funding available. This is particularly challenging within the context of an ageing population as all services will inevitably have to adjust to the complex care needs of a population who will experience "higher levels of dependency, dementia and comorbidity" (Kingstone et al., 2018, p. e447). Aspirations to support residents with chronic as well as life-limiting health conditions to continue to live in $\mathrm{ECH}$ and age in place may require policymakers, commissioners of services and providers to reconsider how health needs are addressed, possibly through initiatives to integrate selected healthcare services in these settings, such as consulting rooms for district nurses. Similarly, planners of new large-scale ECH settings could work with health partners to design co-located health facilities (Housing LIN 2019). ECH was established to provide greater choice in housing settings for older people on the assumption that most residents would not require on-site healthcare delivered by health professionals. However, as we have seen, in a context of restricted funding for public services and the prioritisation of services on those in the greatest need, perhaps we are moving to a position where the ECH model, as it stands, becomes unfeasible for publicly funded residents. Achieving the aspirations of ECH appears to be at odds with a system which prioritises those with the greatest need for care and support and the consequences of this were affecting the experiences of older people living in $\mathrm{ECH}$.

\section{Conclusion}

ECH was developed as an alternative to more traditional forms of residential care for older people in which the provision of social care and support is integrated in a manner that supports older people to live as independently as possible within their own apartment. Although the data presented here suggest that, whilst the model supports many older people to live independently, it is, at times, undermined by wider pressures. In particular, the model is under strain from both funding pressures being experienced in England and the growing number of people with complex needs who are moving into ECH settings. Together, these factors are putting pressure on schemes, undermining assumptions about the balance of care needs amongst residents that lie at the heart of the ECH model, whilst also challenging the idea that ECH can be considered a "home for life".

\section{References}

Age UK (2019), Later Life in the United Kingdom 2019, available at: https://www.ageuk.org.uk/ globalassets/age-uk/documents/reports-and-publications/later_life_uk_factsheet.pdf.

Atkinson, T., Evans, S., Darton, R., Cameron, A., Porteus, J. and Smith, R. (2014), "Creating the asset base: a review of literature and policy on housing with care", Housing, Care and Support, Vol. 17 No. 1, pp. 16-25.

Batty, E., Foden, M., Green, S., McCarthy, L., Robinson, D. and Wilson, I. (2017), "Evaluation of extra care housing in wales", Project Report, Welsh Government, Cardiff.

Callaghan, L. and Towers, A.M. (2014), "Feeling in control: comparing older people's experiences in different care settings", Ageing and Society, Vol. 34, pp. 1427-1451. 
Cameron, A.M. (2016), "What have we learnt about joint working between health and social care?", Public Money \& Management, Vol. 36 No. 1, pp. 7-14.

Cameron, A.M., Johnson, E.K., Lloyd, L., Evans, S., Smith, R., Porteus, J., Darton, R. and Atkinson, T. (2019), "Using longitudinal qualitative research to explore extra care housing", International Journal of Qualitative Studies on Health and Well-Being, Vol. 14 No. 1, doi: 10.1080/17482631. 2019.1593038.

Croucher, K., Hicks, L. and Jackson, K. (2006), Housing with Care for Later Life: A Literature Review. Joseph Rowntree Foundation, York.

Darton, R., Bäumker, T., Callaghan, L., Holder, J., Netten, A. and Towers, A. (2012), "The characteristics of residents in extra care housing and care homes in England", Health and Social Care in the Community, Vol. 20 No. 1, pp. 87-96, doi: 10.1111/j.1365-2524.2011.01022.x.

Department of Health (2013), "Integrated care and support: our shared commitment", available at: https://assets.publishing.service.gov.uk/government/uploads/system/uploads/attachment_data/ file/198748/DEFINITIVE_FINAL_VERSION_Integrated_Care_and_Support_-_Our_Shared_ Commitment_2013-05-13.pdf.

Department of Health (2017), "Next steps on the five year forward view", available at: https://www. england.nhs.uk/wp-content/uploads/2017/03/NEXT-STEPS-ON-THE-NHS-FIVE-YEAR-FORWARD -VIEW.pdf.

Dewing, J. (2008), "Process consent and research with older persons living with dementia", Association of Research Ethics Journal, Vol. 4 No. 2, pp. 59-64.

Evans, S., Atkinson, T., Cameron, A., Johnson, E.K., Smith, R., Darton, R., Lloyd, L. and Porteus, J. (2018), "Can extra care housing support the changing needs of older people living with dementia?", Dementia, doi: 10.1177/1471301218801743.

Holland, C., Carter, M., Cooke, R., Leask, G., Powell, R., Shaw, R. and West, K. (2015), Collaborative research between Aston Research Centre for Healthy Ageing (ARCHA) and the ExtraCare Charitable Trust, available at: www.aston.ac.uk/EasySiteWeb/GatewayLink.aspx?alId=245545.

Housing LIN (2015), Extra Care Housing what Is It?, Housing Leaning \& Improvement Network, London, available at: https://www.housinglin.org.uk/_assets/Resources/Housing/Housing_ advice/Extra_Care_Housing_What_is_it.pdf (accessed 20 May 2019).

Housing LIN (2019), Identifying the Health Care System Benefits of Housing with Care, Housing Learning \& Improvement Network, London, available at: https://www.housinglin.org.uk/_ assets/Resources/Housing/Support_materials/Reports/HLIN_SouthamptonCC_HwC-HealthCare-System-Benefits_Report.pdf.

Johnson, E.K., Cameron, A., Lloyd, L., Evans, S., Darton, R., Smith, R., Atkinson, T. and Porteus, J. (2019), "Ageing in extra-care housing: preparation, persistence and self-management at the boundary between the third and fourth age", Aging \& Society, doi: 10.1017/ S0144686X19000849.

Kingston, A., Comas-Herrera, A. and Jagger, C. (2018), "Forecasting the care needs of the older population in England over the next 20 years: estimates from the Population Ageing and Care Simulation (PACSim) modelling study", The Lancet, Vol. 3, pp. e447-e455.

Looman, E.M., Huijsman, R. and Fabbricottie, I.N. (2019), "The (cost-)effectiveness of preventive, integrated care for community-dwelling frail older people: a systematic review", Health and Social Care in the Community, Vol. 27, pp. 1-30.

Mann, J., Devine, S. and McDermott, R. (2019), "Integrated care for community dwelling older Australians", Journal of Integrated Care, Vol. 27 No. 2, pp. 173-187.

National Audit Office (2017), Health and Social Care Integration, NAO, London.

Phillips, J., Dobbs, C., Burholt, V. and Marston, H. (2015), "Extra care: does it promote resident satisfaction compared to residential and home care?", British Journal of Social Work, Vol. 45, pp. 949-967, doi: 10.1093/bjsw/bct185.
Living in extra care housing 
Smith, R., Darton, R., Cameron, A., Johnson, E.K., Lloyd, L., Evans, S., Atkinson, T. and Porteus, J. (2017), “Outcomes-based commissioning for social care in extra care housing: is there a future?", Housing, Care and Support, Vol. 20, pp. 60-70.

Spencer, L., Ritchie, J., Ormston, R., O'Connor, W. \& Barnard, M. (2014), "Analysis: principles and processes”, in Ritchie, J., Lewis, J., McNaughton Nicholls, C., Ormston, R. (Eds), Qualitative Research Practice. Sage, London, pp. 269-294.

West, K., Shaw, R., Hagger, B. and Holland, C. (2017), "Enjoying the third age! discourse, identity and liminality in extra-care communities", Ageing and Society, Vol. 37, pp. 1874-1897, doi: 10.1017/ S0144686X16000556.

Wild, A., Fraser, S. and Clark, D. (2018), "Mapping the "housing with care" concept with stakeholders: insights from a UK case study", Journal of Integrated Care, Vol. 26 No. 4, pp. 257-266.

Wright, F., Tinker, A., Mayagoitia, R., Hanson, J., Wojgani, H. and Holmans, A. (2010), "What is the 'extra' in extra care housing?", British Journal of Social Work, Vol. 40 No. 7, pp. 2239-2254.

\section{Corresponding author}

Ailsa Cameron can be contacted at: a.cameron@bristol.ac.uk

For instructions on how to order reprints of this article, please visit our website:

www.emeraldgrouppublishing.com/licensing/reprints.htm

Or contact us for further details: permissions@emeraldinsight.com 